\title{
PERFORMANCE MANAGEMENT FOR COMPETITIVE ADVANTAGE \& LEADERSHIP REFLEX
}

\author{
C. N. Narayana, International Management Institute, New Delhi, India
}

\author{
dx.doi.org/10.18374/IJSM-13-1.9
}

\begin{abstract}
This paper is an attempt to synthesize the role of effective leadership for a successful performance management system in modern day organizations and the critical components of performance management system which differentiates a great organization from good. The study also identifies complex and competing ideas about leadership and the common traps of communication skills and the workaround solutions to overcome such hurdles. This study also emphasizes Strategic Management issues in conforming to human relations need, different levels of behavior, individual, group and organizational. It also focuses on developmental needs, rewards and recognition, and employee engagement as strategic tools to achieve organizational objectives on its journey to realizing the vision. An attempt is made to integrate and link leadership role to Performance Management System through Convergence Model.
\end{abstract}

Keywords: Strategic Human Resource management, Performance Management System, Leadership, Communication Strategy 